\title{
Militarisation and Privatisation of Outer Space: A Grave Threat to Humanity
}

\author{
Prabhu Ray Yadav ${ }^{1}$ \\ Patan Multiple Campus, Tribhuvan University, Katmandu, Nepal,
}

\author{
CORRESPONDENCE: \\ Prabhu Ray Yadav \\ Patan Multiple Campus, \\ Tribhuvan University, Kathmandu, Nepal \\ Email: yprabhuray@gmail.com
}

ISSN : 2382-5359(Online), 1994-1412(Print)

DOI:

https://doi.org/10.3126/njst.v20i1.39447

\section{ACCESS THE ARTICLE ONLINE}

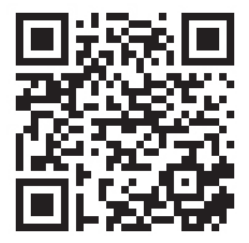

\section{CONFILICT OF INTEREST: None}

Copyright: The Author(s) 2020. This is an open access article under the $\underline{\text { CC BY license. }}$

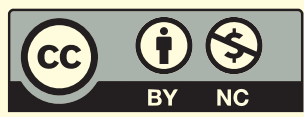

\begin{abstract}
Nations are spending millions of amounts in amassing arms and nuclear weapons on Earth and even in Space. Such a situation is bound to lead humanity to the brink of a catastrophic war on Earth and even in Space. In this context, sensible human beings should oppose all warmongering activities that could ultimately invite the very extinction of humanity. This paper tries to emphasize the consequences of the misuse of arms and ammunition on Earth and in Space. This paper focuses on spreading the need for co-existence of people worldwide and eschews the thoughts of waging a war that may wipe out the humanity's face from the Earth.
\end{abstract}

Keywords: Catastrophic war in Space, co-existence of people, extinction of humanity, nuclear weapons on earth

\section{INTRODUCTION}

The world today is facing a severe existential crisis due to the irresponsible behaviour of human beings. The relationship between ecology and humanity is getting eroded, and concerns have been raised worldwide (Ghoshroy 2019). Climate change has brought an unprecedented crisis leading to an existential threat to humanity. Humanity is at significant risk today because of growing insensitivity of militarily powerful countries instigating militarisation and privatisation under materialistic thought's growing impact.

\subsection{Militarization of Outer Space and its Effect on Human Civilizations}

Outer space lies beyond the Earth between celestial bodies. It is almost empty and vacant, but it is an impenetrable vacuum, where there are more particles. Numerous elements in the cosmology tightly surround these particles. These elements are not yet wholly explored (Izzo 2017). The beauty of the universe is just like an account of the circle of the outer Space. There is a temperature of millions of Kelvi in outer Space (Angali et al. 2007). Studies show that $90 \%$ of the mass in galaxies is unknown to human conscience and knowledge. They are called dark matters to human perception. We know the present age is getting more dangerous because of nuclear bombs production and weaponisation of the Outer Space. So, this paper's main objective is to arouse mass awareness against nuclear weapons' proliferation on Earth and in Space.

The observation of mass is called "dark energy" in an observable universe (Peebles \& Ratra 2003). There is a type of vacuum that is difficult to understand. Outer space has not a definite altitude from the surface of the Earth (Henning 2001). According to the 1967 space treaties, outer space begins at an altitude of $100 \mathrm{~km}$ above the sea level. As per the space law, outer space treaty came into 
force on October 10, 1967. This treaty prohibits the claims of nation and person in Space. U.N. resolution states that Outer Space is just for peaceful uses, yet nations keep on testing anti-satellite weapons in space orbit. Yuri Gagarin, a former Soviet Union scientist, first found Earth Orbit in 1961. Since then unscrewed spacecraft has reached all planets in the solar system. Human crewed spacecraft is highly costly, and it has reduced the Earth orbit and the Moon.

The heavenly or celestial bodies are as expensive as the entire universe. They are known and unknown to the people. The celestial body is any natural body outside of the Earth's atmosphere (Coffey 2009). The celestial bodies in the cosmos region are shown in Figure 1.

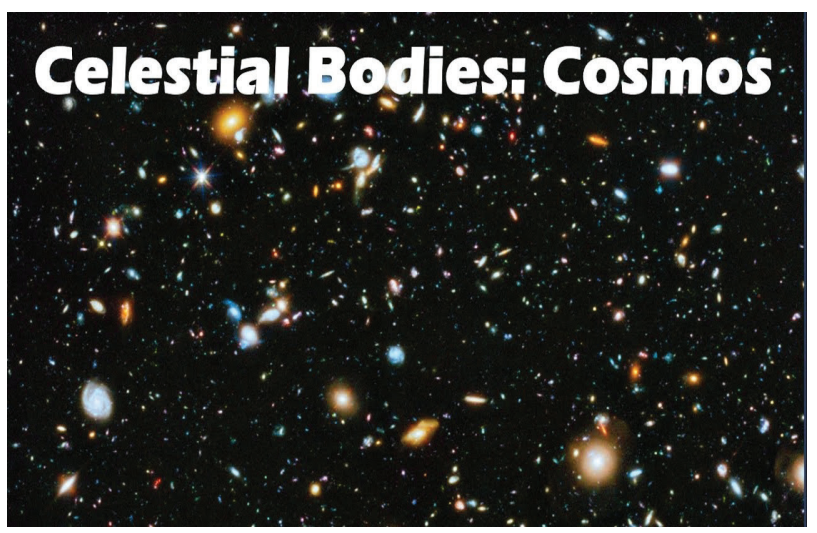

Fig. 1. Celestial Bodies https://www.youtube.com/ watch? $\mathrm{v}=\mathrm{SNcACFUiC7U}$

According to the $17^{\text {th }}$ century French philosopher Rene Descartes, the entirety of space must be filled with celestial bodies (Lilli 2003). According to the Greek philosopher Aristotle's theory and suggestion, nature detests a vacuum. It is this principle that is known as the "'horror vacui". In the same vein, this concept of Aristotle was later propounded as an ontological argument by another Greek philosopher Parmenides. He agrees with the statement that existence in void space is not possible (Raimund 1998). The Chinese astronomer Zhang Heng of the $2^{\text {nd }}$ century affirms that Space must be infinite supporting the Earth, the Moon, the Sun, and the stars. They float moving or standing still there in the Space. Same real thoughts and beliefs are extended, to a great extent, to the principles of German theologians and scientists Nicolaus, Otto von Guericke and Galileo, the Italian scientists. They conclude that there must be a vacuum between the Earth and the Moon (Grant 1981). Thus, the usages and users of fictitious appliances of science and technology must be restricted to better both Space and Earth. The dark energy that is understood by the mystery force is shown in Figure 2.

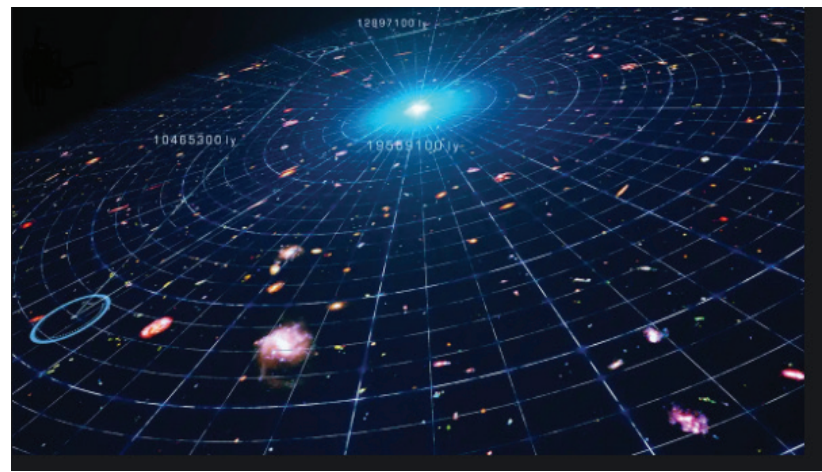

Fig. 2. Dark energy understanding the mystery force https://www.newscientist.com/article/mg24432601-900-

Space exploration began during the $20^{\text {th }}$ century and human crewed rocket launches have followed this. Unscrewed spacecraft has reached all of the known planets in the solar system. Due to the high cost of getting into Space, human crewed spaceflights have been limited to low earth orbit and the Moon. Today, outer Space represents a challenging environment for human exploration because of vacuum and radiation (Barsky \& Robert 2007). Microgravity also hurts human physiology that causes muscle atrophy and bone loss (Chuss \& David 2008). In addition to these health and environmental issues, the economic cost of putting objects, including human being into Space is very high.

People today in the world and their scientific mechanisms invented by them are fraught with threats and dangers arising from them. An American linguist, philosopher, social critic and historian, most notably expresses how commercialist's arrogance of hegemony is vividly seen in the following excerpt from his book titled Democracy and Power:

The goal, as the U.S. Space Command documents explain, is to obtain global dominance, "hegemony" as they call it, and the purpose is (I'm quoting) 'to protect U.S. interests and investments". They also give a history. They say that in the past, countries constructed armies and navies to protect and enhance commercial interests, but now there's a new frontier we can cross. We can take the next step in protecting and enhancing commercial interests and investment, namely the militarisation of Space (Chomsky 2014).

Since the 1950s, the Air Force has mostly been working in the two most basic areas: the first supports the military space operations, and the second, includes all space operations aimed at the effectiveness of terrestrial military operations. These two mission categories traditionally 
have been politically benign with no sensitivities attached. The allies of America acknowledge the American mission of Air Force operated only for nation-building interest. America invests enormous sums of money on both military strength and commercialisation.

By looking at the expenses, the potential opponents begin to threaten and neutralise America's Space-related expenses. The confrontation and tussle between other rich emerging nations are vividly noticed for more than four decades of Air Force operation in space circling program. The space system of America remains on high alert due to the precaution on the part of allies. The mischievous development of militarised and commercialised Space has given rise to the potential adversaries. They inconsistently force American leadership to confront the misuse of vital space systems. Despite the enriched technological age in Space and on Earth, America either seizes the vulgar space operation or confronts its aggressive rival countries. They are uplifting their militarisation and privatisation in the space exploration activities as the following excerpt amply corroborates:

No military or commercial satellites are yet known to carry sensors to detect an attack by lasers, electromagnetic energy, or a kinetic - kill the device. At present, the United States relies solely on passive measures for protecting its on orbit assets against such threats. These measures include hardening and shielding against radiation, orbital manoeuvring capabilities to evade attacks, and to use such means as data encryption and anti-jamming provisions. Hardening of satellites and other onboard protection means offer an interim defense against potential threats. However, those measures are expensive and can be countered by a determined attacker (Lambeth 2003).

\subsection{Effect of Space War on Climate Change}

The relationship between ecology and humanity is getting blurred and eroded, and concerns have been raised worldwide. Climate change has brought an unprecedented crisis leading to an existential threat to humanity. However, powerful countries like France, Germany, Russia, England and America are not attentive to this concern. In this context, weaponisation and militarisation of space has become a serious issue of present day world. While the Earth is already on the brink of destruction, even the Space is not free from pollution and unholy collusion because of the rapid competition among the advanced countries to weaponise the Space. Further, Anti - Satellite Weapons that are used in Space Wars are illustrated in Figure 3.

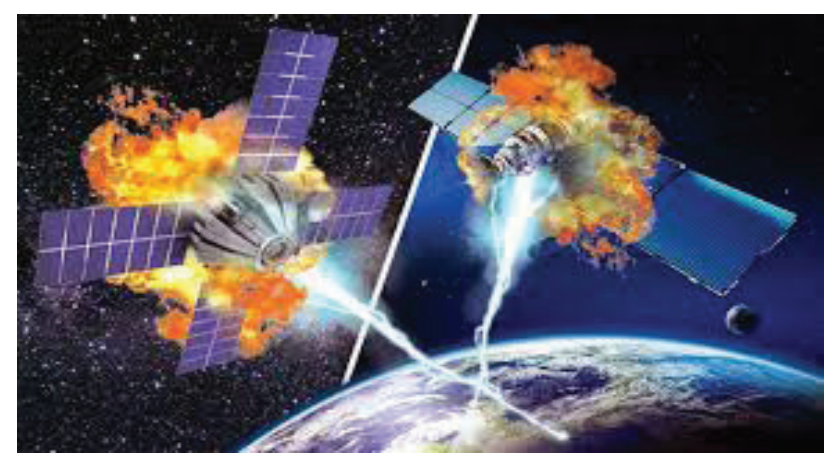

Fig. 3. Anti -Satellite Weapons for Space Wars https:// tacticalinvestor.com/russia-china-developing-anti-satelliteweapons-space-wars/

In the early days of space exploration, superpowers represented the only human presence in outer Space. However, this framework is the subject of many recent changes on various fronts as private enterprises are becoming increasingly and decisively crucial in the space industry. Today, concerns are raised about the impact of increased space activity on our diverse cultural heritages. But the advanced countries are not doing enough to preserve the Space. Some countries hope to make Space tourism as part of the everyday adventure, which is a matter of grave concern for humanity. These countries are aiming to build a permanent colony and broadcast the whole thing as a reality T.V. show. How can we allow these countries to decide about the use of space in the interest of a few and at the cost of immense humanity? The following observations on the use of Air Force and Space Power for the $21^{\text {st }}$ century are significant:

some Air Force commentary in recent years on the wouldbe virtues of space weaponisation has seemed surprisingly oblivious of the real sensitivities that still attach to the idea of combat operations from Space in many quarters, as well as of the no-less-real political costs and potential consequences for our national interests that could accrue from making space force application a premature goal of U.S. strategy. One such example was the space applications volume of the Air Force Scientific Advisory Board's widely publicized New World Vistas study of 1995. The study categorically stated that the Air Force should broaden the use of space to include direct force projection against surface, airborne, and space targets (Cohen, 1984).

The impact of new developments in international Space has increased privatisation and it may change the legal order for space activities. In the past only the USA and the former USSR were known as the only space powers, but today many other countries like India and China have become space powers. This development has 
increased the tendency towards commercialisation and privatisation of the Space for profit-making. Such a race for the privatisation of Space for a commercial purpose is a severe threat to humanity. People need to know about this tendency because ultimately,humanity is bound to suffer from this mad race for the space privatisation. Some eminent Indian thinkers and seers have continued to warn humanity about the looming shadow of destruction. The Principal Scientist of National Dairy Research Institute says:

Destruction of the old world is ready in front of you. They are preparing the bombs so that they can finish everyone off whilst sitting at home. Whilst sitting at home, they may release the bombs in such a way that the whole world could be destroyed (Veena 2016).

The Space exploration was guided by genuine thoughts and interest, but today, the profit-making concept or approach has changed the situation. It is a matter of great concern that the number of users of the Space has increased. More and more governments have started becoming active in space activities for commercialisation and privatization (Chomsky 2003). Unlike in the past, public sector interest has been abandoned. The tendency towards privatisation of Space is more significant in America and European countries. The private launching of Space activities has become a trend in countries like Russia, Ukraine, Kazakhstan, China, India and Pakistan. These countries have private launching capability, and they are engaged in commercial relation of space activities. U.S. President Trump delivered a Presidential Message on the 75th Anniversary of the Trinity Nuclear Test held in New Mexico. Referring to the Manhattan Project which produced the atomic bombs, the message says that it ' 'helped end World War II and launch an unprecedented era of global stability and our nuclear deterrent has also greatly benefitted our Nation and our allies" (Masakazu 2020). Europe is also using the Space for private enterprise on a large scale. Thus, space launching has become predominantly commercialised and privatised, for instance; the international telecommunication enterprise has also been privatized (Gagnon 2017). Today, we find private satellite being used by many countries, mostly in Europe and North America.

As per the rules, international Space should not be governed by private entities. Space tourist activities should also be banned for preserving the Space and saving humanity. International space law should not be softened, and multilateral treaties should be brought into effective practice to avoid the Space privatisation and commercialization. United Nations too should play a vital role in banning the privatisation of the space. If we do not take the matter seriously, it may be impossible to protect health and environment, including all-pervasive climates (Moorcock 2008). We have already seen the consequences of the degradation of the environment and climate change. Recently, a tiny island country the Bahamas, known officially as the Commonwealth of the Bahamas, faced a severe catastrophic impact of environmental degradation. Other countries too, are facing the same problem.

\section{CONCLUSION}

Today, more governments have become private users of the Space; such an increase in the number of users demands more stringent laws and regulations to prevent further privatisation and commercialisation of the Space. Ignoring the growing threat resulting from privatisation of the Space could be a great mistake. All governments and other stakeholders concerned about using outer Space for the peaceful purpose should take it as an obligation including immediate action to prevent the Space privatisation and militarisation. Governments or states do not have any choice except to follow the universal law that demands banning the Space privatisation. People worldwide should heed the call of the time seriously, and voices should be raised to prevent their respective governments from misusing the Space. The relationship between humanity and ecology should be enormously strengthened. It is the way we can save the Earth and Space from total annihilation and destruction.

\section{ACKNOWLEDGEMENT}

I am grateful to the North American citizen Bruce K. Gagnon, the Coordinator of Global Network against Weapons and Nuclear Power in Space, who helped me a lot during my visit to Russia in connection with a conference held in three cities - Moscow, Crimea and St. Petersburg. I received support also from World War II Veterans, intellectuals, economists, politicians, professors, and students of several universities during the Global Network Conference against Weapons and Nuclear Power in Space. I am equally thankful to Prof. Dr. Shreedhar Gautam, Tribhuvan University, for his constant support in my academic pursuit. I want to extend my sincere thanks to the hosts of national and international conferences for giving me this opportunity to share my article in their prestigious institutions among the school and college students. Further, I acknowledge my thanks to Nepal Academy of Science and Technology for providing me with the necessary materials for my research paper. 


\section{REFERENCES}

1. Angalli, Galeazzi, \& Ursino. 2007. XMM-Newton observation of the diffuse X-ray background, the Astrophysical Journal 658 (2), University of Miami IOP press, p. 1081.

2. Barsky \& Roberty. 2007. The Chomsky Effect: A Radical Works Beyond the Ivory Tower, MIT Press, p. 107.

3. Coffey, J. 2009. UNIVERS TODAY: Space and Astronomy News. https:www.universetoday. com>celestial-body

4. Chomsky, N. A. 2014a. Democracy and Power, 'Militarism, Democracy and People's Right and Information, Open Book Publishers.

5. Chomsky, N.A. 2003b. Mastering the Ultimate High Ground: Next Steps in the Military Uses of Space "NO SPACE CONTROL AND SPACE FORCE APPLICATION, RAND Corporation

6. Cohen, A. E. 1984. Systems of Military Service: The Dilemmas of a Liberal-Democratic World Power. US. University Micro films.

7. David, \& Chuss. 2008. NASA Goddar Space Flight Center, Retrieved from http://lambada.gsfc.nasa.gov/ Product/code/2013-04-27.

8. Gagnon K. B. 2017. SpaceAlert!" Global Network Newsletter \#34" (ed.) Brunswick.

9. Ghoshroy, S. 2019.India's Successful Anti-Satellite Test. Space Alert! Vol. 38.
10. Grant, E. 1981. Much Ado about Nothing: Theories of Space and Vacuum from the Middle Ages to the Scientific Revolution. Cambridge University Press. pp. 18 www.space4peace.org (207) 607-4255

11. Henning, G. 2001. Nothingness: The Science of Empty Space. Da Capo Press, pp. 127-128.

12. Izzo, J. 2017. The Five Thieves of Happiness. Oakland, CA: Berrett - Koehler Publishers, p. 7.

13. Lambeth, S. B. 2003.Mastering the Ultimate High Ground: Next Steps in the Military Uses of Space "NO SPACE CONTROL AND SPACE FORCE APPLICATION, RAND Corporation.

14. Lilli. A, 2003, Descartes's Concept of Mind, Cambridge: Harvard University Press.

15. Masakazu, Y, 2020. Japan Council against $A$ and $H$ Bombs (Gensuikyo), Press, P. 15.

16. Moorcock, M. 2008. Brave New Worlds. The Guardian.London, Retrieved 25 August https://www.theguardian.com/books /2008/mar/22/ artjircce; arle

17. Peebles \& Ratra. 2003. The Cosmological Constant and Dark Energy. Rev. Mod. Phys. 75, 559

18. Raimund, K. P. 1998. The World of Parmenides. Routledge.ISBN0-415-17301-9.

19. Veena, M. 2016. Are we evolving or developing? - A rejecting theory. The World Renewal Vol.47. Retrieved from https://bkarticlesblog.files.wordpress. com/2020/06/may-2020- world- enewal.pdf 